\title{
How Employer Interests and Investments Shape Advanced Skill Formation
}

\author{
Lukas Graf, University of St. Gallen, Switzerland \\ Justin J. W. Powell, University of Luxembourg
}

I $\mathrm{n}$ many countries around the world, higher education today offers the most assured pathways to secure careers and low unemployment rates. Yet, increasingly some groups-not least the college graduates and their families who are paying ever-higher tuition fees-question the long taken-for-granted contributions that higher education makes to individuals and society as a whole (Schulze-Cleven 2015). Despite mass expansion, societies struggle to achieve their goal of "college for all"-due in part to limited public or corporate funding for affordable study opportunities. Although participation rates have climbed worldwide, higher-education systems continue to produce winners ("insiders") and losers ("outsiders"), even as the "schooled society" shifts the occupational structure upward (Baker 2014). Furthermore, market-oriented higher-education systems, notably in the United States and the United Kingdom, face increasing privatization, which also involves financializing university governance (see Eaton in this symposium). Many states have retrenched investments that had once underwritten the flourishing of universities and their moves toward massification. Tensions have deepened over who should pay for rising costs (see Garritzmann in this symposium), exacerbated in an era of increasing status competition via higher education. In the face of such challenges globally, which alternatives exist?

A prominent possibility, pioneered in Germany in the $1970 s$, is the "dual-study" program. These hybrid programs fully integrate phases of higher-education study and paid work in firms; students are simultaneously trainees. In the short term, firms receive inexpensive labor; in the medium term, they benefit from personnel trained in the relevant context. Yet, firms invest not only in recruiting and training motivated future full-fledged employees. They also collaborate with higher-education institutions to develop specific curricula that promise to craft skilled workers needed in the future. In these programs, employers and educators cooperate to provide coursework in "dual"-learning settings: on campus and in the workplace. Together, they shape a labor force oriented toward current challenges and opportunities in specific sectors, such as engineering and economics or business.

Dual-study programs manifest ways in which employer interests and investments are shaping advanced skill formation.
They produce new skills at the nexus of higher education and workplace-based training. We argue that contemporary developments in Germany provide an innovative approach to simultaneously strengthen education and the economy. Co-developed and co-financed by employers, these programs have many advantages. Benefits include encouraging employers to at least partially fund their own skill supply. This could moderate the global trend toward saddling students and families with ever-higher education costs and debt.

Grounded in neo-institutional analysis, expert interviews, and document analysis, we focus on the relationship between higher education and firms in Germany, Europe's largest economy. First, we introduce the historical-institutional context of advanced skill formation in Germany. Second, we analyze the rapid expansion of dual-study programs. In particular, we emphasize the importance of employer interests and highlight distributional conflict in the new politics of skill investment. Third, we present lessons that the United States might learn from these hybrid programs.

\section{CHARACTERIZING ADVANCED SKILL FORMATION IN GERMANY}

Germany, the birthplace of the modern research university (Baker 2014), has among the strongest research-intensive higher-education systems in Europe, and it continues to be a reference point for other countries across disciplines. In contrast to heavily market-oriented systems such as in the United States, higher education in Germany is considered a public good and is provided nearly tuition-free regardless of nationality. This is also due to student protests against implementation of tuition fees (Hüther and Krücken 2014).

Simultaneously, Germany's traditional secondary-level apprenticeship system, which links workplace training with vocational schooling in particular occupations, also continues to be attractive globally (Euler 2013; Powell and Solga 2010). Dual apprenticeship training at the upper-secondary level has a celebrated history in Germany, firmly embedded in corporatist governance structures that involve employer and employee representatives from business associations and unions as so-called social partners (Busemeyer and Trampusch 2012). These programs lead to recognized certification according to the Vocational Training Act and the 
Crafts Code, thereby governing access to specific occupations (Thelen 2004).

Both higher education and vocational training in Germany have often provided policy inspiration for other countries (Phillips 2011). However, the German skill-formation system is currently undergoing reforms to address lacking institutional permeability between the organizational fields of higher education and vocational training (Graf 2013). Indeed, the strengths of these fields-each defined by distinct rules, norms, and practices-led to a persistent divide between them, known as the "educational schism" (Baethge and Wolter 2015). This division has long hindered educational and social mobility and today presents a major problem, not least due to socio-economic developments such as the growth of the knowledge economy, tertiarization, and increasing educational expectations. In this context, dual-study programsoperating at the higher-education level-can provide answers because they promise to facilitate needed flexibility in educational careers and lifelong learning for all. Yet, how did these "hybrid" programs at the nexus of vocational training and higher education emerge? and thereby reducing the financial burden on families. Dual studies provide a sought-after pathway for young adults to learn and earn simultaneously, which-crucially-enables young adults to jumpstart their careers. For employers, these programs attract, mature, and maintain valuable talent.

The core principle of these programs is their interactive combination of the workplace and the seminar room. These two distinct learning environments offer necessary but differing opportunities to gain practical and academic knowledge. Dual-study programs are most common in economics, engineering, and computer science, but they also are growing in other disciplines, such as health-related fields (Graf et al. 2014). Thus far, subjects have been concentrated in areas close to growing economic sectors. Students apply directly to the firm, which in turn collaborates with the university to provide academic education. All involved parties-the student, the firm, and the university-are bound by a formal agreement, and students continue with the same firm for their entire undergraduate study period. The firm is responsible for financing the in-firm training. It also pays the student a salary, typically equivalent to or higher than that received by traditional apprentices

\section{In this context, dual-study programs-operating at the higher-education level-can provide answers because they promise to facilitate needed flexibility in educational careers and lifelong learning for all. Yet, how did these "hybrid" programs at the nexus of vocational training and higher education emerge?}

\section{THE EXPANSION OF WORK-BASED HYBRID STUDY PROGRAMS IN GERMANY}

German employers, especially in manufacturing, initially launched dual-study programs to ensure the practical relevance of the academic skills that higher-education graduates acquire. Responding to this challenge, employers in the $1970 \mathrm{~s}$ began to cooperate with various types of educational organizations to build dual work-based academic programs at a higher level. By uniting firm-based training with postsecondary academic education in applied courses of study, these new hybrid programs facilitate making the most of technological change and academic upgrading of curricula.

In the past decade, this unique feature of Germany's highereducation system has expanded markedly (Bundesinstitut für Berufsbildung 2015). In joining elements of apprenticeship training and higher education, this specific type of workbased higher education accomplishes institutional-boundary spanning, especially with regard to curricula, teaching staff, and funding. Such connections between the learning environments of the firm and the academy extend far beyond the summer internship or abbreviated on-the-job training common in the United States. When teachers in academic organizations and employers work together in systematic ways to design curricula, they ensure that students have learning opportunities guided not only by academic faculty but also by company experts. Employers cover the costs of training during the praxis term, paying students for their work and studies, in the respective industry. A large portion of the costs for the program's academic part is state-financed because most dual-study programs are offered through public universities (of applied sciences). However, when firms cooperate with a private university, they usually cover much or all of the incurred costs.

Dual-study programs usually lead to a bachelor's degree in about three to four years (dual studies at the master's level are still rare but also expanding) and connect two didactic principles: namely, scientific grounding and practical training. The original type of dual-study programs integrates an initial vocational-training certificate. Here, graduates attain double qualifications-an upper-secondary-levelvocational-training certificate and a bachelor's degree from the university, thereby improving access to specific occupations.

Notably, the impressive recent expansion of such workbased higher-education programs in Germany is due more to employer initiative rather than government or party politics. Whereas in Germany, state (i.e., Länder) governments as well as the federal government are the decisive players in regulating and financing higher education, this is only partly true for dual-study programs. Rather, collaboration between employers and universities is crucial, with these programs developed from the bottom up (Graf 2013). This is indicative of an innovative development in German higher education that resonates with certain developments in the United States. What has long been acknowledged and valorized in the United States-namely, that higher-education institutions are strong 
organizational actors in their own right-is increasingly evident in Germany as differentiation proceeds and universities develop more specific profiles.

This emergent field of work-based higher education exhibits similar cleavages and coordination challenges that exist in the traditional dual-training system. Key arenas of contention include the provision of training and its financing as well as the related mechanism of control and public oversight (see Busemeyer and Trampusch 2012 on dual training at the secondary level) but also the conflictual politics of general versus specific skills more broadly (Streeck 2012). In the seems to be left behind is the union, traditionally a key partner in German skill formation. Whereas German unions concentrate on the governance of traditional dual-apprenticeship training, their attention to developments in higher education has been limited as they struggle to win tertiary graduates as a major new source of members. Thus, in an era of structural changes in the economy and rising educational expectations and attainment, unions have difficulty in realizing opportunities with regard to strategies for advanced workplace-based training. This is even more relevant given that a lack of union involvement could result in these programs focusing too narrowly on firm-specific skills.

\section{What has long been acknowledged and valorized in the United States-namely, that higher-education institutions are strong organizational actors in their own right-is increasingly evident in Germany as differentiation proceeds and universities develop more specific profiles.}

traditional German dual vocational education and training (VET) system (at the upper-secondary level), a balance among the various interests of the involved stakeholders-capital, labor, and the state-is feasible due to the tradition of practiced corporatism. In contrast, in the field of higher education, we encounter a largely unexplored terrain of negotiations and, crucially, decentralized cooperation (Culpepper 2003) around work-based training programs developed by higher-education institutions and firms-more or less collaboratively.

However, research on the political economy of skills thus far has mainly focused on the study of the traditional dual-training system at the secondary level as one of the hallmarks of corporatism in German capitalism (Hall and Soskice 2001). Thus, given recent developments, the political-economy approach to skills requires adaptation to account for more recent developments in higher education (Graf 2009; Hölscher 2012). When political economists analyze skill formation, they tend to be especially interested in the role of firms (or employer associations) and trade unions in the VET system. Yet, as the dual-study principle is upgraded to the tertiary level, employers take center stage in negotiating new governance forms of higher education. Consequently, we observe changing constellations and coalitions of actor groups within higher education. We argue that the interactions of these groups, including employers and universities and their associations, among others, provide fruitful ground for future political science analyses of skill formation and higher education.

\section{THE POLITICAL STAKES IN UPGRADED WORKPLACE- BASED TRAINING}

Dual-study programs represent shifting lines of conflict in the governance of advanced skill formation. Crucially, through the bottom-up development of such schemes, two actors have gained influence relative to the others: employers as original drivers behind dual-study programs and universities as entrepreneurial actors in their own right. In contrast, the actor that
Furthermore, current institutional innovations may well undermine traditional high-level dual-study apprenticeships at the secondary level-as these are gradually shifted to higher education. However, lower-skill apprenticeships are not being similarly upgraded; therefore, dual-study programs are unlikely to close the gap between high- and low-skill sectors but rather are more likely to academize the medium sector of traditional apprenticeships (e.g., in industry and commerce occupations). The losers might be those who would have previously gained access to traditional medium-skill occupational training but are now potentially left behind as academization accelerates. Thus, we find the paradoxical dynamic in Germany that, initially, dual-study programs were thought of as potential equalizers but now mainly top secondary-school graduates are selected them. Nevertheless-and especially from a trade-union perspective-dual studies in principle could offer those without sufficient capital to invest in higher-education opportunities to successfully complete college. This participation would provide access to attractive career pathways. More generally, dual-study programs tackle issues stemming from limited market absorption at the nexus of vocational training and higher education. When successful, they embed employers' knowledge about current and future skills demands into advanced skill formation.

\section{OPPORTUNITIES AND CHALLENGES OF HYBRID PROGRAMS LINKING HIGHER EDUCATION AND EMPLOYMENT}

Work-based higher education in the form of dual studies is quickly becoming a key element in the German highereducation system. This development is more likely to be successful if these programs invest equally in the provision of high-level academic skills and hands-on practical skills. Employers increasingly demand this combination in recruiting talented young people for high-level training programs. More broadly, the combination and feedback processes between educational organizations and firms promise innovation at the nexus of education 
and economy. This, in turn, opens up new perspectives for the transatlantic comparison of advanced skill formation.

In an era of growing constraints on public funding in many countries, such programs facilitate needed private investments in higher education. This development relates to the blurring of traditional boundaries between higher education and vocational education and training in many countries around the world (Powell and Solga 2010), which also is reflected in a gradual convergence of these fields across Europe (Powell et al. 2012). In the United States as well, some work-based higher-education programs resemble the German dual-study programs, including higher-end apprenticeship programs offered by American community colleges as well as a vast range of co-op programs (Graf 2016). However, these US variants too often do not successfully or sufficiently combine workplace and academic learning.

In this context, a key lesson that can be learned from the German case is the need to build structures that allow highereducation organizations and employers to cooperate and to overcome potential conflicts between the worlds of academia and work. Compared to traditional vocational training, universities are more alike in Germany and in the United States. Thus, universities' relations with firms can be relatively similar and private actors and discourage detrimental dynamics that threaten the collective spirit of work-based skill formation, this type of dual-study higher education may lead firms to invest more heavily in high-quality, tertiary-level education programs as well as salaries for student employees. Finally, a key principle of such a system is that employers and the state jointly cover the costs of work-based higher education. These costs would be balanced by benefits such as integrated curricula, enhanced firm competitiveness, and better skill matching.

Another strength of dual-study programs is the high degree of curricular integration between the two learning environments of the university and the firm. Yet, this ideal tends to be quite challenging to implement in practice. In Germany, the institutional conditions are favorable partly due to a long-standing tradition of collective governance in the field of work-based training through the key stakeholders, including educational organizations, employers, trade unions, and state agencies. The dual-study programs' integration of a formal vocational-training certificate and a bachelor's degree illustrates this crucial collaboration. In these programs, the Chambers of Commerce are involved, for example, in examining candidates for vocational-training certification. To foster the cooperation

\section{In this context, a key lesson that can be learned from the German case is the need to build structures that allow higher-education organizations and employers to cooperate and to overcome potential conflicts between the worlds of academia and work.}

in the two countries, especially with increased privatization and the growing need for private investments in education. However, what is crucial is inter-employer coordination, which can be facilitated by local and national intermediary organizations (e.g., business associations and chambers) that facilitate the joint development of such programs and prevent "free-rider" problems related to poaching. In these settings, firms understand that they have to pay (more) for the advanced skills they require, which may involve greater private costs in training programs and student salaries. It also implies investments in academic skills that transcend immediate firm-specific skills. Concurrently, the academy faces the challenge of developing tools that ensure systematically integrated work- and theory-based learning experiences. For this, university representatives must leave the "ivory tower" to see eye to eye with employers.

As a recent development, the insertion of the dual-study principle of vocational training into German higher education provides both opportunities and risks. At the intersection of higher education and vocational education, these programs imply increasing corporate influence in higher education. Simultaneously, expanding work-based higher-education programs may stimulate innovation, with this closer linkage of higher education to the economy facilitating advanced, practice-oriented skill formation while potentially spurring social mobility-within and beyond higher education. Thus, if policy makers set the right incentives for decentralized cooperation between public of all involved actors and enhance the necessary fine-tuning between the learning experiences in the university and the workplace, it seems worthwhile to explore how cooperative study programs in the United States could offer a double qualification: a bachelor's degree and a registered apprenticeship certificate. An additional advantage is that if students realize that achieving a bachelor's degree is too demanding for them, they still have the fallback option of earning a registered apprenticeship certificate. Where this reduces college-dropout rates, it would save the loss of human capital and help individuals to qualify for entry into skilled-labor markets.

Another potential advantage of apprenticeship training being offered in conjunction with higher education is that it would boost the reputation of apprenticeships overall. Experiences from countries including Germany and Switzerland show that the attractiveness of the apprenticeship-training system as a whole is bolstered when it also offers a viable pathway for those individuals with a traditional university-entrance certificate. If these students seriously consider and choose advanced work-based higher education, this well may increase the standing of practice-oriented training among students, their families, and employers. Thus, when considering strategies to improve skill formation overall, reducing the costs that individuals must bear in attaining higher education, and improving the fit between educational expectations of employers and potential employees, dual-study programs provide an innovative model for policy making on both sides of the Atlantic. 


\section{ACKNOWLEDGMENTS}

We gratefully acknowledge the American Institute for Contemporary German Studies at Johns Hopkins University and the German Academic Exchange Service for supporting this research.

\section{REFERENCES}

Baethge, Martin and Andrä Wolter. 2015. "The German Skill Formation Model in Transition." Journal for Labour Market Research 48 (2): 97-112.

Baker, David P. 2014. The Schooled Society: The Educational Transformation of Global Culture. Stanford, CA: Stanford University Press.

Bundesinstitut für Berufsbildung. 2015. AusbildungPlus in Zahlen: Trends und Analysen 2014. Bonn, Germany: BIBB.

Busemeyer, Marius R. and Christine Trampusch (eds.). 2012. The Political Economy of Collective Skill Formation. Oxford: Oxford University Press.

Culpepper, Pepper D. 2003. Creating Cooperation: How States Develop Human Capital in Europe. Ithaca, NY: Cornell University Press.

Euler, Dieter. 2013. Das duale System in Deutschland: Vorbild für einen Transfer ins Ausland? Gütersloh, Germany: Bertelsmann Stiftung.

Graf, Lukas. 2009. "Applying the Varieties of Capitalism Approach to Higher Education: Comparing the Internationalization of German and British Universities." European Journal of Education 44 (4): 569-85.

- 2013. The Hybridization of Vocational Training and Higher Education in Austria, Germany and Switzerland. Opladen, Germany: Budrich UniPress.

_. 2016. "Betrieblich-hochschulbasierte Ausbildungsformen in Deutschland und den USA: Eine (Re)Konzeptualisierung." Zeitschrift für Pädagogik 62 (3): 323-39.
Graf, Lukas, Justin J. W. Powell, Johann Fortwengel, and Nadine Bernhard. 2014 "Dual- Study Programmes in Global Context: Internationalisation in Germany and Transfer to Brazil, France, Qatar, Mexico and the US." Dok\&Mat 77. Bonn, Germany: German Academic Exchange Service.

Hall, Peter A. and David D. Soskice (eds.). 2001. Varieties of Capitalism: The Institutional Foundation of Comparative Advantage. New York Oxford University Press.

Hölscher, Michael. 2012. "Spielarten des Kapitalismus und Kompetenzen von Hochschulabsolventinnen und -absolventen." Kölner Zeitschrift für Soziologie und Sozialpsychologie 64: 479-505.

Hüther, Otto and Georg Krücken. 2014. "The Rise and Fall of Student Fees in a Federal Higher Education System: The Case of Germany." In Students, Markets and Social Justice, ed. Hubert Ertl, and Claire Dupuy, 85-110. Oxford: Symposium Books.

Phillips, David. 2011. The German Example: English Interest in Educational Provision in Germany since 180o. London: Continuum.

Powell, Justin J. W., Lukas Graf, Nadine Bernhard, Laurence Coutrot, and Annick Kieffer. 2012. "The Shifting Relationship between Vocational and Higher Education in France and Germany." European Journal of Education 47 (3): 405-23.

Powell, Justin J. W. and Heike Solga. 2010. "Analyzing the Nexus of Higher Education and Vocational Training in Europe." Studies in Higher Education 35 (6): 705-21.

Schulze-Cleven, Tobias. 2015. "Liberalizing the Academy." In Research $\mathcal{E}$ Occasional Paper Series: CSHE.1.15. Berkeley: University of California, Center for Studies in Higher Education.

Streeck, Wolfgang. 2012. "Skills and Politics." In The Political Economy of Collective Skill Formation, ed. Marius R. Busemeyer and Christine Trampusch, 317-52. Oxford: Oxford University Press.

Thelen, Kathleen. 2004. How Institutions Evolve: The Political Economy of Skills in Germany, Britain, the United States, and Japan. New York: Cambridge University Press. 